more in length. The Association will follow the same procedure described above for complete articles. The fee to the APSA for a table, figure, or selection is $\$ 50$ and the author's fee, if requested, will be $\$ 50$ to $\$ 100$. The author will also have the option to request the right to review any selection in which deletions or editorial changes have been made.

The Association's reprint permissions policy reflects the advice of its Committee on Publications and printiples specified in its $A$ Guide to Professional Ethics in Political Science.

\section{The American Political Science Association Policy and Procedures for Permission to Copy Articles for Class Assignments, April 1992}

The Association wishes to facilitate the classroom use of articles in its journals, The American Political Science Review and PS: Political Science \& Politics. The policy and procedures to accomplish this objective consider the needs of faculty and students who use the articles and protect the rights of the authors and the Association which holds the copyrights.

To assure access to articles, there is no fee and no prior clearance requirement for the first 10 copies of an article. In other words, up to, but no more than 10 copies can be made of a single article, either to be distributed directly to individual students in a small class or to be placed on reserve in a library.

The Association's permission to copy and distribute any article(s) must be requested if more than 10 copies will be produced. This applies to the distribution of any article(s) separately, as well as to any article(s) that are included in a special reader or text prepared for a faculty member by a copying service.

The request for permission to copy one or more articles must be accompanied by:

- a full citation of the article(s);

- the title of the course in which it is assigned;

- the name of the course's instructor who is assigning the article; and

- the number of copies that are to be made.

The fee for more than 10 copies of an article is $75 \mathrm{c}$ for each additional copy. Prepayment of these fees is required unless specific prior arrangements have been made.

The Association will expedite the permissions process to assure that materials can be distributed when students will need them.

The Association's policy on copying articles for class use has been prepared by its Committee on Publications and reflects principles specified in the APSA's A Guide to Professional Ethics in Political Science.

\section{Congressional Fellowship Program Announces 1992-93 Competition Winners}

\section{Political Scientists, Reporters Named APSA Congressional Fellows}

The American Political Science Association has announced the winners in the national competition for the 1992-93 Congressional Fellowship Program. Following a one-month orientation seminar, Fellows work full time for nine months as professional staff assistants to Members of Congress or congressional committees.

The new Political Science and Journalism Congressional Fellows are:

Denise L. Baer, Associate Professor, Department of Political Science, University of Akron

Mark C. Curtis, Senior News Reporter, WEAR-TV, Pensacola, Florida

Maureen Groppe, Staff Writer, South Bend Tribune, Indiana

Howard A. Isenstein, General Assignment Business Reporter, The New Haven Register, Connecticut

Shannon LeHere, former Deputy Bureau Chief, Westinghouse Broadcasting, Washington, DC

Craig A. Rimmerman, Associate Professor and Chair, Department of Political Science, Hobart and William Smith Colleges

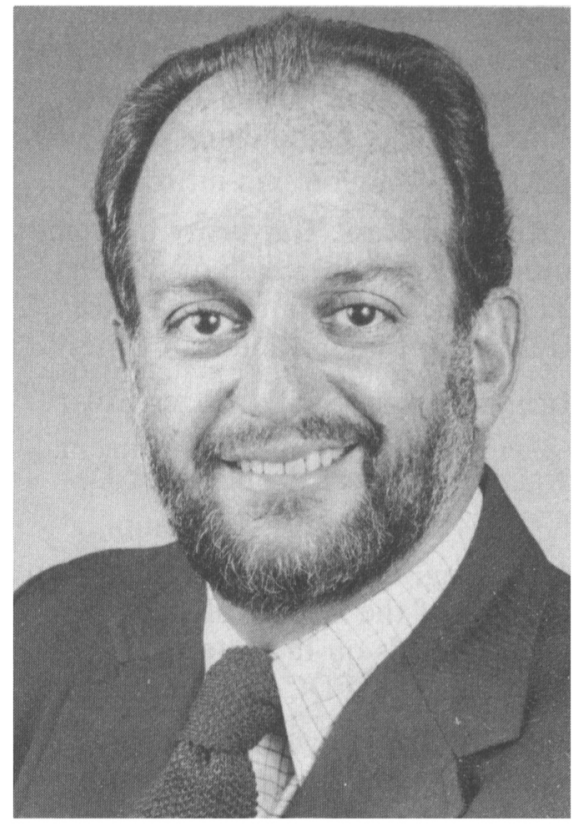

Peter L. Rosegg

Peter L. Rosegg, Editorial Writer, The Honolulu Advertiser

David J. Webber, Associate Professor of Political Science, University of Missouri-Columbia

\section{Federal Executives Win Congressional Fellowships}

The Association also selected 22 federal executives as Congressional Fellows for the 1992-93 program and expects to name two more before September.

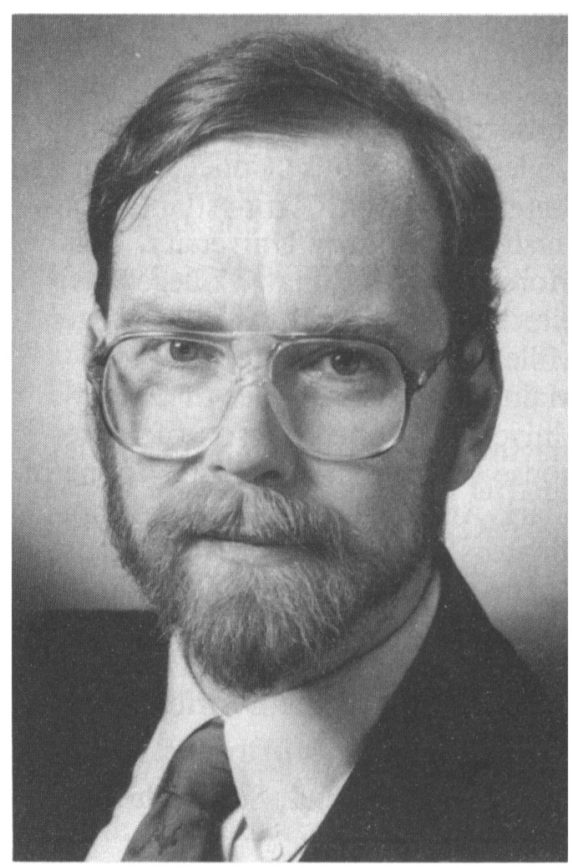

David J. Webber 